\title{
Literature and Participatory Culture Online: Literary Crowdsourcing and Its Discontents
}

\author{
Hanna Kuusela \\ University of Tampere, Finland \\ hanna.kuusela@uta.fi
}

\begin{abstract}
This article discusses literary crowdsourcing in the context of critical media studies and aesthetic theories that stress participation. First, it draws an overall picture of the participatory culture or social turn in literature, focusing on literary crowdsourcing and the social values and hopes attached to it. Second, the article discusses the challenges literary crowdsourcing faces, arguing that today's cultural, economic and media environments render the practice vulnerable to different social, economic and aesthetic discontents. Asking to what extent literary crowdsourcing is able to uphold its promises of social value in the literary and media environment characterised by platform capitalism, precarious labour, communicative capitalism and affective economics, the article offers critical tools for analysing literary crowdsourcing and participatory online practices in art.
\end{abstract}

Keywords: affective economics; collaboration; collaborative literature; crowdsourced literature; crowdsourcing; literary crowdsourcing; participatory culture; platform capitalism

\section{Introduction}

The 21st century has seen a wave of literary projects that engage people in the processes of writing in a variety of ways. Different textual installations, performances and collaborative events have encouraged participation, and writing collectives and reading events have once again become popular, creating a new participatory culture in literature. Most notably, the participatory trend can be seen in literary crowdsourcing, which has become a common practice. In the past two decades, numerous artists and organisations have invited crowds to collaborate digitally in the writing of novels, poems and opera librettos, while other artists have delegated the process of literary writing to microworkers on digital platforms. Together, such practices have strengthened the participatory dimension in literature and shifted the focus from literary texts to the processes of writing.

This article discusses literary crowdsourcing as an example of the larger participatory trend in contemporary literature and explores the phenomenon in the context of critical media studies and aesthetic theories that stress participation. First, it draws an overall picture of the 
participatory culture (Jenkins et al. 2006 or social turn (Bishop 2006; 2012) in literature, focusing on the practice of literary crowdsourcing and the social values and hopes attached to it. Second, it offers a critical perspective on the challenges literary crowdsourcing faces and its possible social, economic and aesthetic discontents in today's world. The article asks to what extent literary crowdsourcing is able to uphold its promises of social value in the existing literary and media environments characterised by so-called platform capitalism (Srnicek 2016), precarious labour positions (Harvie 2013), communicative capitalism (Dean 2005) and affective economics (Hills 2015; Jenkins 2006). Or do these practices rather serve the needs of contemporary forms of capitalism and the culture industry?

Critical media and art scholars have raised similar concerns about participatory cultural practices, but these perspectives have only occasionally entered literary criticism. Given the emphasis on participation and collaboration in both contemporary art and media (Hjorth and Sharp 2014, 129), I believe the discussion of participatory practices in the digital sphere benefits from a cross-disciplinary approach. Hence, by focusing on the possible discontents, this article introduces to the discussion on literary crowdsourcing aspects that are often missing. This choice of focus does not entail that literary crowdsourcing could not have any positive effects, but that this potential for positive outcomes needs to be examined critically.

\section{The Social Turn, Participatory Culture and Literature}

In the past few decades, collaboration, participation and the production of relations (Bourriaud 2002) or dialogical encounters (Kester 2004) have been major trends in aesthetics, and different forms of socially engaged or community- and process-based art have dominated much of the art world (Siegenthaler 2013). Artists increasingly emphasise social practices, networks and processes as constituting the actual artwork, instead of the art object, and events that facilitate social interaction are seen as the actual art practice (Siegenthaler 2013, 738). From Nicholas Bourriaud's (2002) relational aesthetics to Grant Kester's (2004) dialogical aesthetic, aesthetic theories have cherished "collaborative practices which emphasize the process and experience of collective interaction" (Kester 2006, 10), promoted art practices that strive "to achieve modest connections" (Bourriaud 2002, 8-9), and been concerned with the creation of "new modalities of social interaction" (Kester 2006, 14). Such tendencies have gradually shifted the artistic focus from art objects to their collaborative or dialogic production (Rutten 2016, 298) and the accompanying social value. Interest in such socially engaged and participatory practices has become so widespread that Claire Bishop $(2006,178)$ has termed it the social turn 
in arts, meaning the "surge of artistic interest in collectivity, collaboration, and direct engagement with specific social constituencies."”

Simultaneous with this aesthetic trend, media scholars have mapped the rise of the so-called participatory culture, meaning a cultural environment characterised by "low barriers of artistic expression and civic engagement" and feelings "of social connections" (Jenkins et al. 2006, 7). Having its roots in the fan cultures of the offline era (Jenkins 2006), participatory culture has been understood as a culture with strong support for creating and sharing one's creations, and also one in which members feel social connection with one another (Jenkins et al. 2009, 7).

What was perhaps first some form of fringe culture (Jenkins 2006, 2), turned mainstream with the rise of digital technologies. According to this line of argumentation, digitalisation has encouraged increased participation in the making of culture (Delwiche and Henderson 2012 Swiss and Burgess 2013, 73), advancing and promoting further a culture of active participation. Such online participation is associated with heightened connectivity and potential for sharing information, connecting people and ideas usually kept apart, and facilitating collaboration (Literat and Glăveanu 2016, 331).

Gradually, out of these participatory impulses, both in the art world and in the online cultures, grew a phenomenon of crowdsourced art that Ioana Literat $(2012,2964)$ defines as the "practice of using the Internet as a participatory platform to directly engage the public in the creation of visual, musical, literary, or dramatic artwork." Weaving together the different impulses, Literat $(2012,2963)$ explicitly sees the integration of crowdsourcing into artistic production as an "outgrowth of recent trends in culture and art coupled with the emergence of a feasible platform that could make this collaboration possible."

Literature has not remained untouched by these trends. In the past few decades, processorientation, social practices and participatory impulses have inspired many authors to initiate projects that have shifted the focus from the literary texts to their collaborative or participatory processes of writing. This can be seen, for example, in the increased popularity of literary collaborations (Kuusela 2015), procedural writing and literary performances and installations (Caduff 2015). Together, these participatory forms that emphasise collaborative processes over the literary text have constituted literature's own participatory culture and social turn. 
Finally, also in the literary field, a number of projects have started to rely on crowdsourcing, creating a phenomenon of literary crowdsourcing that can be defined as a practice of inviting through an open call a large pool of Internet users to contribute to the writing of a literary text. This definition includes many common characteristics associated with crowdsourcing, understood as the act of delegating tasks openly to an undefined network of people, or a general Internet public, in the form of an open call (Estellés-Arolas and González-Ladrón-de-Guevara 2011).

In the following, this phenomenon of literary crowdsourcing is investigated by concentrating on the hopes and promises attached to the practice and its possible discontents. Even though the focus is primarily theoretical and conceptual, the article makes use of empirical analysis to highlight how certain discontents that deserve more discussion figure in different projects. The material discussed consists of literature's paratexts, the various texts that accompany the literary text. Rather than offering any close reading of specific crowdsourced texts, the article examines the so-called reading formations surrounding these texts, meaning the set of determinations that organise the social relations of reading and structure the interactions between texts and readers (Bennett 1983; for reading formations as a method, see Kuusela 2013). To do this, the article explores how participatory impulses in literary crowdsourcing are represented and discussed in different texts surrounding literary texts, such as author interviews, reviews, journalistic articles, press releases, project descriptions and discussions on social media platforms. The empirical examples used in the article derive from a larger research project on collaborative practices in contemporary literature. The paratexts analysed here were primarily collected online by using both general search words around literary crowdsourcing (such as literature + crowdsourcing; crowdsourced novel/poem/book; literature + participation), and specific search words for each project (such as the name of the project and its initiator), but important paratexts that constitute the reading formations also appear, for example, in dust jackets, book covers, research reports, and in print media. For this article, no participants of literary crowdsourcing have been interviewed, but instead the social imageries that travel along with literary crowdsourcing, for example, in journalism and project descriptions, have been studied in order to examine how the possible discontents appear and find form in such public paratexts. For all the projects discussed here, the initiator's descriptions of the project have been analysed (these include, e.g. press releases and project descriptions on web pages), and depending on the project, from 10 to 30 paratexts per project that different receivers have produced (such as reviews and social media commentaries). The 
analysis of the paratexts focuses particularly on those passages that concern participation and the role of participants, asking how the projects, their participants, participation itself, and the rationale for it are described and addressed in the paratexts.

By studying the paratexts, the article shows how literary crowdsourcing is structured and presented to readers and potential participants and how these formations reveal its potentialities and hopes as well as the challenges that render it vulnerable to various social, economic and aesthetic discontents.

\section{Literary Crowdsourcing and Its Promises}

Literary crowdsourcing has become a popular term but it often remains undefined. This reflects the state of the discussion on digital participation in literature more generally, as the discussion lacks a common vocabulary. The term "networked book," for instance, has been used to refer to "an open book designed to be written, edited and read in a networked environment" (Vershbow 2006), while Scott Rettberg (2011) has written of "network-based collective narratives" and "collective web narratives." Thomas Swiss and Helen Burgess (2012 73) have used the concept "collaborative new media poetry" to refer to "poetry in the context of networked and programmable media involving multiple 'authors' working in conjunction with one another." In this context, literary crowdsourcing, as defined above, is a useful concept both as an umbrella term for earlier concepts and as a term that helps differentiate projects based on open calls from other types of online collaborations.

Many early projects that delegated literary writing to online crowds through open calls were not yet named crowdsourcing. For example, a famous early example, A Million Penguins (2007), possessed all the basic principles of crowdsourcing but was not identified as such. Instead, this project, which invited contributions on a wikiplatform over five weeks, was called a "collaborative novel open to anyone who wanted to help write it" (Mason and Thomas 2008). The term "crowd" was used to refer to the writers, but the word "crowdsourcing" was not attached to this project organised by De Montfort University and the publisher Penguin. Similar massive online collaborations relying on open calls and initiated by commercial companies or large organisations include the sci-fi novel Crowd Control (2016) by the technology site CNET, the novel Necklace (2012) by the newspaper Sydney Morning Herald, the novel Lonely Wish-Giver (2014) by the company Grammarly, the novel Pirunmeri (2011) by the Finnish publisher WSOY, and crowdsourced Twitter novels organised, for example, by BBC 
Audiobooks and Blackberry, such as A Calendar of Tales, which author Neil Gaiman wrote with Twitter users.

Smaller-scale crowdsourced projects include, for example, Collabowriters, initiated by artist Willy Chyr, who invited people to write a crowdsourced novel line by line; La Familia, a project by the poet laureate Juan Felipe Herrera that welcomed crowds to contribute fragments under different themes; a project by poet Dan Simpson who crowdsourced poetry by releasing topics on social media to solicit responses from which he composed poems; and the Iowa Bird of Mouth project that invited people to write poetry on birds. Other projects have invited participants not to write but to comment on evolving texts. For example, author Silvia Hartmann let her audience comment as she drafted her novel The Dragon Lords in a public Google document.

Such crowdsourced projects often come with great hopes and promises and are typically discussed in enthusiastic language (Kuusela 2016). As, for example, poet and writer Sean Hewitt (2012) writes:

Crowd-sourcing is just one way in which we can open up a poetic conversation in our country: it puts the production of literature back in the hands of the people, and can give us an interesting insight into new ways of thinking and new ways of seeing the world.

Hewitt sees in literary crowdsourcing the possibility to allow multiple, diverse voices in the public sphere instead of a singular authorial voice (Hewitt 2012):

Instead of hearing a single voice, we hear a chorus, and the harmony is often in the discord. It offers the opportunity for people of all professions and lifestyles to contribute, and allows us to place a steady finger onto the pulse of our country's diverse culture.

Hewitt's views recall the larger discourse on participatory art, which attaches participatory practices to different social and artistic causes (Bishop 2006, 12). Jen Harvie (2013, 1-2) suggests that participatory practices in the arts hold up the heady promise of enormous social value in two ways: first, they seem to offer widespread constructive social engagement, with participants communicating, collaborating, and mutually supporting one another. Second, they appear to extend this invitation to engage very widely, across all audiences equitably, perhaps even democratically. These features_-social engagement and fair, democratic opportunityhave also become increasingly cherished in literature, especially in its crowdsourced forms. 
For example, the promotions for La Familia (2015) claim that by contributing "you will be part of [the author's] family — and all our words will be seen and our voices be heard, throughout the nation and beyond." Similarly, the initiator of Iowa Bird of Mouth states that with the project, she wanted to get people to write who have always wanted to create a poem, but have been frightened to, and declares that the project "is a great place to share your words and be a part of the community" (Davis 2016). The project's website uses the vocabulary of communality, proposing that "in a crowdsourced poem, anyone can contribute their words. The technique offers a great opportunity to expand definitions of community and engagement" (Iowa Bird of Mouth 2017).

In addition to communal values, participatory art is typically thought to challenge the hierarchies of the art world. Participatory and collaborative impulses in art are frequently attached not only to social causes but also to a wish to cede authorial control from the individual artist in favour of more egalitarian creation (Bishop 2006, 12). This theme recurs in discussions on literary crowdsourcing. Hartmann, author of The Dragon Lords, declares that her project was "an amazing opportunity for [her] as an author to push the boundaries of the author/reader relationship" (Hartmann 2012). In the same spirit, Gaiman's Twitter novel was regarded as "democratizing inspiration" (Blackwell 2013), and the initiator of Collabowriters speaks against the single voice (in Day 2012):

I think because there isn't one single voice guiding the course of the novel, it's going to break a lot of the rules that more traditional works follow. Every person that enters a submission brings something new to the table.

Like other forms of participatory art, literary crowdsourcing thus seems to carry high hopes of social value and more egalitarian creation. Similar to the artists working in participatory and relational art, who tend to see participation through an optimistic, micro-utopian lens, and as a solution to the problems endemic to the established forms of cultural engagement (Bishop 2006 Beech 2008; Foster 1996; Literat 2012), literary crowdsourcing is also often presented as a critical response to literary elitism and the passivity of the reader.

Whether different projects live up to these promises, however, remains an open empirical question. Participatory techniques do not automatically guarantee progressive or democratising outcomes, and participation is not intrinsically politically progressive (Harvie 2013, 10), even if we believed in its democratic and social potential. It is vital, therefore, that we see 
participatory art as a particular form of "cultural engagement with its own constraints, problems and subjectivities" (Beech 2008).

In addition to exploring how literary crowdsourcing may extend equal opportunities for social engagement, criticism thus should pay attention to how actual projects may also constrain those opportunities (Harvie 2013, 10). The second part of this article, therefore, investigates the possible discontents of such practices. It focuses on the discontents, leaving more positive aspects aside, in order to highlight the less discussed dimensions of literary crowdsourcing. Following Harvie $(2013,3)$, it starts by asking:

Who can participate and on what terms? What is the quality of participation, and how does it vary for different participants in changing contexts? How do these artistic trends articulate contemporary social understandings of the individual and the social?

\section{The Discontents of Literary Crowdsourcing}

\section{Social Discontents: Precarious Participants and Reproduced Authors}

Who gets to do what and where, when and how in projects of literary crowdsourcing? The projects introduced in this article have permitted different degrees of authorial and editorial control. Some have allowed the participants to write freely on topics of their choosing, whereas in many projects, the initiators have used the participants' contributions primarily as inspiration. In such projects, the editor-author decides the themes of the writing or chooses and edits the crowds' contributions. For example, in the "world's first crowdsourced sci-fi novel" (Mack 2015), Crowd Control, CNET worker Eric Mack posted his writing in a public Google document to which participants could (only) make suggestions. Rather than granting all contributors equal power over the text, Mack integrated suggestions from the crowd into his draft and posted an update every evening. Similarly, Mikko Karppi, acknowledged as the main author of Pirunmeri, gave the contributors daily writing tasks. He then chose the best suggestions and rewrote the final text. In La Familia, Herrera welcomed contributions of words or fragments from everyone but only on the themes he decided, and in Iowa Bird of Mouth, the contributors were asked to write specifically about local birds.

In short, the nature of participation varies significantly among projects, and despite the common ethos of openness, communality and democratisation, power is almost always unequally distributed. In practice, participation in crowdsourced art is not as universally open, inclusive and egalitarian as we would like to think (Literat and Glăveanu 2016). Therefore, it 
is vital to resist the tendency to romanticise or idealise online participation. Literat $(2012,2975)$ notes that participation should not be used as a blanket term, since it does not account for the complexities of creative agency, artistic hierarchies, access, and capital in different projects. In reality, there are subtle degrees of participation in art, and a closer analysis reveals a complex ladder of participation (Literat 2012, 2975).

In some projects of literary crowdsourcing, participants are fully conscious of the project's nature and how their contributions might be utilised, but in others, their participation is only contributory, to use Rettberg's (2011 term denoting projects in which contributors may not be aware of how their contributions fit into the project but, nevertheless, take conscious steps to make them available. Similarly, Literat $(2012,2975)$ has written on receptive and executory participation in which participants' engagement is limited, as opposed to structural participation where participants can also contribute structurally to the project.

A great number of projects and the discourses surrounding them neglect critical questions concerning the actual nature of decision making and the degree of democracy in the projects, instead employing an undetailed vocabulary of participation, a problem familiar in the larger debates on participatory culture (Fuchs 2014, 68-70). Although some projects, like Collabowriters, have granted participants decision-making power through voting, many keep power solely in the hands of the initiator(s).

In doing so, contributory participation, with the divisions it entails or helps support, may resemble the insecure conditions in today's social reality and the labour market, as Harvie $(2013,46)$ has suggested. According to her, participatory art often requires audiences to respond to the leading artists' prompts in ways that put the participants in precarious positions. Thus, writes Harvie $(2013,46)$, the “audience's work is insecure, in that they do not know what they are going to be called upon to do." Such insecurities characterise many projects of literary crowdsourcing, as the (aforementioned) projects based on prompts suggest. In A Calendar of Tales project, for example, Gaiman asked a question on Twitter every hour, to which the followers responded. Such projects follow those forms of participatory art where the participant is not cast as an agent of critique or subversion but rather as one who is invited to accept the parameters of the project (Beech 2008). Consequently, depending on the project's architecture, participatory projects may reproduce, rather than subvert or challenge, the precarious conditions of our societies. As Harvie $(2013,46)$ notes, flexible spectatorship (or the crowds 
in literary crowdsourcing) resembles "the conditions of flexible labour: people are called on to work with co-workers and audiences whom they do not know."

Such divisions between creative decision makers and contributory participants are not only embedded in the architectures of many projects but also reproduced in the reading formations around them. Most cases discussed here (re)produce the boundaries between the author or the artist and the crowds so that the paratexts variously call the participants "readers," "fans," "crowds," "users," "followers" or "the audience" but only rarely "authors" or "artists." This language recurs in both the initiators' paratexts and the media paratexts. An example is a news article on Crowd Control, which differentiates between the named initiator and the "readers" who are presumed to "help" him: "CNET's Eric Mack introduced readers to a basic premise for a sci-fi novel and asked them to help him write it" (Arreola 2016). Similarly, the project Pirunmeri included "a main author," and media coverage of the Collabowriters called Willy Chyr "the Chicago-based artist" and "the creator," and the writers "users" and "the crowd" (Day 2012).

Similar division is found in a news story on Gaiman's project. According to the journalist, "when Gaiman asked his 1.8 million Twitter followers for story ideas in February, he launched a project that allowed professionals and amateurs alike to work with their idol" (Blackwell 2013). The journalist notes that "writers, artists, and fans rushed to give their 140-character answers in the hope of catching Gaiman's interest" (Blackwell 2013). Gaiman is understood as the agent of the project whose attention, not the participants' expanded agency, is desired. This story entitled "Neil Gaiman Sets Twitter Ablaze with Fan Collaboration" constantly uses the categories of idols, fans, authors, amateurs and followers in ways that hardly redistribute the symbolic power of the author.

The cultural, rhetorical and practical persistence of such categories urges caution when making claims about the (re)distribution of artistic subjectivity or authorial power in participatory projects. To the contrary, the function of the crowds may also turn out to support the named, professional artist rather than challenge the divide between them (see also Kuusela 2016). Harvie $(2013,47)$ writes that participatory crowds "create the spectacle and help concentrate focus on the key players." They "become sword carriers, usually with no swords" $(2013,47)$. Similarly, writers of crowdsourced literature are constantly at risk of becoming authors with no authority or authorial power. Literary crowdsourcing projects may give participants a 
passing feeling of artistic agency and inclusion but in ways that, in Harvie's (2013, 3) words, "can only ever be temporary and limited" and rarely effect significant changes in the structures of artistic production. This can be seen not only in the vocabulary used in the projects but even more so in the media discourses that concentrate on the figure of the artist, treating the participants as crowds, readers or users. This is an old but still relevant problem also discussed in the context of the ethnographic turn in art, where Hal Foster $(1996,306)$ has questioned art's ability to create equal relationships, observing that "[a]lmost naturally the focus wanders from collaborative investigation to 'ethnographic self-fashioning' in which the artist is not decentred so much as the other is fashioned in artistic guise."

\section{Economic Discontents: Platform Capitalism and Affective Economics}

Large media companies have organised many popular literary crowdsourcing projects, such as A Million Penguins, The Necklace, The Lonely Wish-Giver, Pirunmeri and Crowd Control, while technology companies have sponsored others. One of Gaiman's projects was realised in collaboration with Blackberry, and Hartmann's The Dragon Lords was launched at Google's London headquarters where she praised Google Docs (Olanoff 2012). Such links between literary crowdsourcing and big business invite an exploration of the political economy of the phenomenon. Many critics describe crowdsourcing as a practice that integrates users in the internal processes of value creation. Instead of stressing its democratising aspects, they present crowdsourcing as a form of un(der)paid work, noting that "the essence of crowdsourcing is the intentional mobilization for commercial exploitation of creative ideas and other forms of work performed by consumers" (Kleemann, Voß and Rieder 2008, 22). Crowdsourcing puts consumers in danger of exploitation as cheap suppliers of valuable ideas without control over their use $(2008,23$.) This view grows from the larger critical discussion on the exploitation of users as free labour in digital media (Fuchs 2014; 2013; Terranova 2000). Simultaneously voluntarily given and unwaged, enjoyed and exploited (Terranova 2000, 33), such free labour forms the basis of digital economy or communicative capitalism (Dean 2005).

From this perspective, many literary crowdsourcing projects not only celebrate the creative skills of amateurs but also make use of the participating crowds as a (free or low-paid) source of value in ways that do not change their position in the structures of (literary) production. Rather than only democratising literary production or fixing social bonds (Bishop 2012), the trend may also produce literature fully commensurate with the contemporary forms of communicative capitalism (Dean 2005) that rely on audience participation through digital 
platforms owned by multinational companies. According to Christian Fuchs (2014, 68-70), the discourse on participatory culture (e.g. Jenkins 2006) often ignores the issues of democracy, collective decision-making, platform and company ownership, profit, class and the distribution of material benefits.

How do the projects discussed in this article fit in these critical discussions? The approach to immaterial ownership varies among projects. Some create texts that remain the organisers' intellectual property, but many projects, such as Crowd Control and Iowa Bird of Mouth, have also published under creative commons licenses. Questions concerning the political economy of such projects, however, do not end with the issue of copyright as the digital economies behind these projects are more complex. Many projects have drawn thousands of engaged users to the organisers' platforms. Indeed, media stories about the projects often highlight the number of participants, suggesting that their key elements are quantitative. According to the organisers of A Million Penguins, nearly 1,500 people "contributed to the writing and editing," and 75,000 people visited the site, resulting in "more than 280,000 page views" (Gorski 2007). The Crowd Control organisers note that "several hundred people contributed" (Mack 2016), while "several hundred people" wrote and voted in the Collabowriters (Day 2012). These contributors not only express themselves and expand their artistic agency but also provide traffic and data for the digital platforms, creating value in the context of platform capitalism, a term used to describe current capitalism reliant on a business model premised upon bringing traffic on different platforms (Srnicek 2016). Some projects also directly promote new platforms: Hartmann "cloud-sourced" her book in Google Docs, and Gaiman's project was realised on Twitter and Blackberry.

Platforms need committed users, and in this respect, the participants in literary crowdsourcing projects are especially valuable. Large contributory crowds are useful in marketing as they widely promote projects for free. A blogger who contributed to The Lonely Wish-Giver praises it on her blog: "I'm really excited about this book. It's my first published novel! Somewhere around 300 authors worked together to create this novel for Grammarly, Inc.- So exciting, now I have a book to publicize, just like all the 'real' writers" (Block 2014). As the enthusiastic tone implies, such participants not only create data but also offer their affects to the organising companies. They thus contribute to the projects' affective economics that seek to make use of and mobilise consumers' emotions and engagements (Hills 2015; Jenkins 2006, 61-2). In affective economics-a key dimension of the political economy of participatory culture- 
consumer action is commodified according to the emerging goals of the brand community, while companies strive to create commodities that resemble decommoditised entities, working their way into consumer sentiment and identity (Hills 2015, 185). The literary crowdsourcing projects discussed attempt to create such brand communities around, for example, Twitter, Sydney Morning Herald and Penguin, and in this spirit, the blogger offers her affective commitments to the company while ignoring their use in marketing. Similarly, Simpson, who has experimented with crowdsourced poetry, writes about the enthusiastic affects surrounding literary crowdsourcing somewhat cynically. He states that a "crowdsourced poem is a brilliant way to involve people in poetry" and can "serve as something of an interesting and engaging marketing tool." He quotes the participants in his projects to demonstrate their engagement: It was :an exciting way of making people feel included in the creative process," and "I felt like I'd made a real contribution to the poem. I felt like a poet," they write (Crowdsourced Poetry 2017). Once again, the project did not turn the participants into artists but gave them a feeling of being included and "like a poet" but not quite a poet.

The analysis of the political economy of participatory art is still in the early stages. However, with the rise of affective economics, the so-called attention economy (Terranova 2012), and the importance of digital virality in promoting commodities and engaging consumers, the economic significance of creative practices is growing. Companies use artists to bring attention to their products, and crowdsourced literature seems closely tied to such promotional needs (Kuusela 2016). Whether literary crowdsourcing then is merely a new economic strategy designed to meet the requirements of platform capitalism and affective economics is a question worth posing and one that we are better equipped to answer after analysing its aesthetic potential.

\section{Aesthetic Discontents: From Artistic Values to Social Values?}

Finally comes the question of the aesthetic value of crowdsourced literature. What kind of value(s) do such texts have from a literary or aesthetic perspective? This is a difficult, if not an impossible question to answer in any straightforward manner. Thus, rather than giving any simple answers, or instead of engaging with the wide debates on how to define aesthetic value, the article will here only raise the question of what may happen to questions of artistic or aesthetic value in and around projects of literary crowdsourcing. It asks how issues concerning value or evaluation seem to figure in the reading formations around literary crowdsourcing: 
what kind of (aesthetic) criteria or practices and regimes of value (Frow 2014) are, or are not, called into being when literary crowdsourcing is discussed?

At first look, based on some literary reviews, it seems that many projects of literary crowdsourcing are not exactly praised for their aesthetic qualities. Many crowdsourced texts do not receive much critical appraisal as texts and the occasional reviews of crowdsourced literature tend to disparage their literary quality. "The first crowd-sourced scifi novel is not very good," a critic writes of Crowd Control (Sturgeon 2016). Similarly, a participant in The Dragon Lords writes, "I'm not saying it's cracking stuff. It's fairly bonkers, to be honest" (Flood 2012).

With a closer look, though, the question of value becomes more complex. Following the wider process orientation in art (Bourriaud 2002; Kester 2006; Siegenthaler 2013), not all commentators perceive the literary text as an important element. In various responses to literary crowdsourcing, the commentators downplay the significance of the resulting text, ignoring questions of aesthetic value, and instead stress the importance of the process and the practice. The regimes of value (Frow 2014, 100-1) that are called into being, or referred to, are not primarily aesthetic, but in some broad sense social. Thus, in the case of literary crowdsourcing, the set of institutional and semiotic conditions that permit the construction and regulation of value $(2014,100-1)$ seem to be something other than literary or aesthetic. A commentator named Dave (2007) contends regarding A Million Penguins: "This is a great idea! Who cares if the end result isn't perfect-it's a cool way for writers to get together and (be) collaborative. Shame on the naysayers!" Dave suggests that the collaborative nature of the process exceeds any possible shortcomings of the literary text to the extent that the result should not even be criticised. Similarly, a colleague comments (in advance) on Gaiman's collaborative Twitter novel: "Because Neil Gaiman is doing the writing, the quality of narrative is high, but that isn't what matters. It's the process and the participation" (Blackwell 2013). A blogger writing on Crowd Control similarly shifts focus from the text to the process. After observing that the book is quite basic in nature, she concludes that "the amount of energy and work that has been poured into this crowdsourced novel cannot go unappreciated" (Douglass 2016).

Such comments invite us to look closer at Bishop's (2006) argument, according to which emphasis on the social dimensions of participatory practices may have overtaken aesthetic considerations to such an extent that participatory art tends to escape traditional aesthetic 
criticism. For Bishop (2006, 180), the urgency of the political task attached to collaborative art practices has led to the automatic perception of such practices as equally important artistic gestures of resistance — or, in the case of literary crowdsourcing, perhaps gestures of artistic democratisation or community building. When artistic participation, with its potential for more democratic, active and egalitarian citizenship, readership or subjectivity, is presented as the main objective of a specific project, it appears difficult to find expression or space for questions concerning other possible values, such as aesthetic or artistic values. As Bishop (2006) notes, these practices are less concerned with a relational aesthetic than the creative rewards of collaborative activity. Consequently, there can be no failed, unsuccessful, unresolved or boring works of participatory art as all are equally essential to the task of strengthening the social bond (Bishop 2012, 13). Whether such participatory gestures will suffice to keep literary crowdsourcing alive or whether its novelty will soon wear out is a question for the future.

\section{Conclusions}

Literary crowdsourcing can be understood as a trend with roots both in the participatory culture of the digital age (Jenkins 2006) and the social turn in arts (Bishop 2006). Consequently, it is vulnerable to many of the challenges these broader trends have faced and open to the same criticisms. When analysing the mundane realities of literary crowdsourcing and the high hopes attached to it as two sides of the same coin, one may ask with Harvie $(2013,3)$ to what extent socially turned or crowdsourced art, in fact, sometimes offers a spectacle of communication and social engagement rather than a qualitatively and sustainably rich and even social engagement.

Finally, it can be asked whether in their social attraction and popularity, such practices are complicit with the poetics of fascism as defined by Paul Morrison (1996, 6-7). Morrison (1996) discusses fascism's tendency to respond to real social needs with an aesthetic pseudocommunity, providing an illusion of collective experience through aesthetic means without changing property relations. It would certainly be hyperbolic to call crowdsourced literature fascist, but it is worth asking whether-akin to fascism in politics_crowdsourced art is in danger of giving people a chance to express themselves without truly changing in any meaningful way how they relate to each other economically and politically.

Discussing the possible discontents does not suggest that all projects are equally vulnerable to the same challenges. To the contrary, the fate of social progress and emancipatory subjectivity 
in literary crowdsourcing depends heavily on how the projects are planned, and their potential needs to be understood in relation to the subjectivities they allow. The challenge facing literary crowdsourcing - and collaborative and participatory art more generally —is whether they can produce (either) the desired positive social effects or texts of some meaningful value. In many cases, the answer to both questions is still a hesitant no, but with the help of constructive criticism, the future may look different.

\section{References}

Arreola, C. 2016. "CNET Begins Publishing Crowdsourced Sci-Fi Novel 'Crowd Control."” Bustle, May 10. Accessed August 1, 2017. https://www.bustle.com/articles/160009-cnet-beginspublishing-crowdsourced-sci-fi-novel-crowd-control.

Beech, D. 2008. "Include Me Out!” Art Monthly 315. Accessed April 12, 2018. https://www.artmonthly.co.uk/magazine/site/issue/april-2008.

Bennett, T. 1983. "Texts, Readers, Reading Formations." Bulletin of the Midwest Modern Language Association 16 (1): 3-17. https://doi.org/10.2307/1314830.

Bishop, C. 2006. “The Social Turn: Collaboration and Its Discontents.” Artforum 44 (6): 178-83.

Bishop, C. 2012. Artificial Hells: Participatory Art and the Politics of Spectatorship. London: Verso.

Blackwell, L. 2013. "Neil Gaiman Sets Twitter Ablaze with Fan Collaboration.” PC World, March 18. Accessed August 1, 2017. http://www.pcworld.com/article/2030776/neil-gaiman-setstwitter-ablaze-with-fan-collaboration.html.

Block, L. 2014. "The Lonely Wish-Giver.” April 23. Accessed August 1, 2017. https://libbyblock.wordpress.com/2014/04/23/the-lonely-wish-giver/.

Bourriaud, N. 2002. Relational Aesthetics. Dijon: Les Presse Du Reel.

Caduff, C. 2015. "Kollektive Autorschaft. Zu den Literaturkollektiven GRAUKO (Graz), Bern ist überall (Schweiz) und G13 (Berlin)." Zeitschrift für Germanistik 25 (1): 132-46. https://doi.org/10.3726/92148_132.

Crowdsourced Poetry. 2017. "About.” Accessed August 1, 2017. https://crowdsourcedpoetry.wordpress.com.

Dave. 2007. "Comment on the Post: A Million Penguins—-the More the Merrier." March 2. Accessed August 1, 2017.

http://thepenguinblog.typepad.com/the penguin blog/2007/02/a million pengu.html.

Davis, L. 2016. "English Professor Begins Crowdsourced Poetry Project.” Iowa State Daily, September 20. Accessed August 1, 2017.

http://www.iowastatedaily.com/news/academics/article_39da2ac0-7f9e-11e6-b244$\underline{\text { 8bf79dfc20db.html. }}$

Day, J. 2012. "Introducing the Collabowriters.” IdeaScale, May 22. Accessed August 1, 2017. 
https://ideascale.com/introducing-the-collabowriters/.

Dean, J. 2005. "Communicative Capitalism: Circulation and the Foreclosure of Politics." Cultural Politics 1 (1): 51-74. https://doi.org/10.2752/174321905778054845.

Delwiche, A., and J. Jacobs Henderson, eds. 2012. The Participatory Cultures Handbook. London: Routledge.

Douglass, A. 2016. "Book Review—Crowd Control: Heaven Makes a Killing." Word of the Nerd, May 9. Accessed August 1, 2017. http://wordofthenerdonline.com/2016/05/crowd-control.

Estellés-Arolas, E., and F. González-Ladrón-de-Guevara, F. 2012. "Towards an Integrated Crowdsourcing Definition.” Journal of Information Science 32 (2): 189-200. https://doi.org/10.1177/0165551512437638.

Flood, A. 2012. "Watch a Novel Being Written 'Live."” The Guardian, September 12. Accessed April 12, 2018. https://www.theguardian.com/books/booksblog/2012/sep/12/novel-written-live.

Foster, H. 1996. "The Artist as Ethnographer?" In The Return of the Real: The Avant-Garde at the End of the Century, edited by H. Foster, 171-203. Cambridge, MA: MIT Press.

Frow, J. 2014. The Practice of Value: Essays on Literature in Cultural Studies. Perth: UWA Publishing.

Fuchs, C. 2013. "Social Media and Capitalism." In Producing the Internet. Critical Perspectives of Social Media, edited by T. Olsson, 25-44. Göteborg: Nordicom.

Fuchs, C. 2014. Social Media: A Critical Introduction. London: Sage. https://doi.org/10.4135/9781446270066.n2.

Gorski, K. 2007. "Creative Crowdwriting: The Open Book." Wired, July 9. Accessed August 1, 2017. https://www.wired.com/2007/07/creative-crowdwriting/.

Hartmann, S. 2012. "Silvia Hartmann Is the Naked Writer. See a Fantasy Fiction Novel Being Written before Your Eyes!" November 26. Accessed August 1, 2017. http://silviahartmann.com/live/.

Harvie, J., 2013. Fair Play_Art, Performance and Neoliberalism. London: Palgrave Macmillan. https://doi.org/10.1057/9781137027290.

Hewitt, S. 2012. "Crowd-Sourcing Poetry.” Huffington Post, September 7. Accessed August 1, 2017. http://www.huffingtonpost.co.uk/sean-hewitt/crowdsourcing-poetry b 1858068.html.

Hills, M. 2015. "Veronica Mars, Fandom, and the 'Affective Economics' of Crowdfunding Poachers." New Media and Society 17 (2): 183-97. https://doi.org/10.1177/1461444814558909.

Hjorth, L., and K. Sharp. 2014. "The Art of Ethnography: The Aesthetics or Ethics of Participation?" Visual Studies 29 (2): 128-35. https://doi.org/10.1080/1472586X.2014.887261.

Iowa Bird of Mouth. 2017. “About.” Accessed August 1, 2017. http://www.iowabirdofmouth.com/about.

Jenkins, H. 2006. Fans, Bloggers, and Gamers: Exploring Participatory Culture. New York: New York University Press. 
Jenkins, H., K. Clinton, R. Purushotma, A. J. Robison, and M. Weigel. 2006. Confronting the Challenges of Participatory Culture: Media Education for the 21st Century. Chicago: John D. and Catherine T. MacArthur Foundation.

Kester, G. H. 2004. Conversation Pieces: Community and Communication in Modern Art. Berkeley: University of California Press.

Kester, G. 2006. "Collaboration, Art, and Subcultures." Caderno Videobrasil 02-Art Mobility Sustainability, Associação, Cultural Videobrasil 2: 10-35.

Kleemann, F., G. G. Voß, and K. Rieder. 2008. "Un(der) Paid Innovators: The Commercial Utilization of Consumer Work through Crowdsourcing." Science, Technology and Innovation Studies 4 (1): 5-26.

Kuusela, H. 2013. "On the Materiality of Contemporary Reading Formations: The Case of Jari Tervo's Layla.” New Formations 78 (18): 65-82. https://doi.org/10.3898/NeWf.78.03.2013.

Kuusela, H. 2015. "Writing Together. Mapping the Terrain of Contemporary Collaborative Writing." Scriptum. Creative Writing Studies 2 (1): 103-35.

Kuusela, H. 2016. "Collective Writing Projects Online and the Challenges of the Promise Economy." Camera Obscura: Feminism, Culture, and Media Studies 31 (3 (93)): 65-97. https://doi.org/10.1215/02705346-3662009.

La Familia 2017. "The Poetry and Literature Center at the Library of Congress." Accessed August 1, 2017. https://www.loc.gov/poetry/casadecolores/familia/index.html.

Literat, I. 2012. "The Work of Art in the Age of Mediated Participation: Crowdsourced Art and Collective Creativity." International Journal of Communication 6: 2962-984.

Literat, I., and V. P. Glăveanu 2016. "Same but Different? Distributed Creativity in the Internet Age." Creativity: Theories, Research, Applications 3 (2): 330-42.

Mack, E. 2015. "CNET’s Crowdsourced Sci-Fi Novel Is Being Written Right Now." November 3. Accessed August 1, 2017. https://www.cnet.com/news/cnet-crowdsourced-sci-fi-novel-isbeing-written-right-now/.

Mack, E. 2016. “"Crowd Control” Contributors.” CNET, May 9. Accessed August 1, 2017. https://www.cnet.com/news/crowd-control-crowdsourced-cnet-novel-contributors-list/.

Mason, B., and S. Thomas. 2008. "A Million Penguins Research Report.” Accessed August 1, 2017. http://www.ioct.dmu.ac.uk/projects/millionpenguinsanalysis.html.

Morrison, P. 1996. The Poetics of Fascism: Ezra Pound, T. S. Eliot, Paul de Man. New York: Oxford University Press.

Olanoff, D. 2012. "Watch This Author Use a Google Document to Write and Edit a Book in RealTime." Tech Crunch, September 18. Accessed August 1, 2017. https://techcrunch.com/2012/09/18/watch-this-author-use-a-google-document-to-write-andedit-a-book-in-real-time/.

Rettberg, S. 2011. "All Together Now: Hypertext, Collective Narratives, and Online Collective Knowledge Communities.” In New Narrative: Stories and Storytelling in the Digital Age, 
edited by R. Page and B. Thomas, 187-204. Lincoln, NE: University of Nebraska Press. https://doi.org/10.2307/j.ctt1df4h49.15.

Rutten, K. 2016. “Art, Ethnography and Practice-Led Research.” Critical Arts: South-North Cultural and Media Studies 30 (3): 295-306. https://doi.org/10.1080/02560046.2016.1205317.

Siegenthaler, F. 2013. "Towards an Ethnographic Turn in Contemporary Art Scholarship." Critical Arts: South-North Cultural and Media Studies 27 (6): 737-52. https://doi.org/10.1080/02560046.2013.867594.

Srnicek, N. 2016. Platform Capitalism. Cambridge: Polity.

Sturgeon, J. 2016. “The World's First Crowdsourced Sci-fi Novel Isn't Good.” Flavor Wire, May 10. Accessed August 1, 2017. http://flavorwire.com/575594/the-worlds-first-crowdsourced-scifi-novel-isnt-good.

Swiss, T., and H. Burgess. 2012. "Collaborative New Media Poetry: Mixed and Remixed." In The Participatory Cultures Handbook, edited by A. Delwiche and J. Jacobs Henderson, 73-81. London: Routledge.

Terranova, T. 2000. "Free Labor: Producing Culture for the Digital Economy." Social Text 18 (2 (63)): 33-58. https://doi.org/10.1215/01642472-18-2_63-33.

Terranova, T. 2012. "Attention, Economy and the Brain.” Culture Machine 13 (0). http://www.culturemachine.net/index.php/cm/article/view/465.

Vershbow, B. 2006. "Defining the Networked Book: A Few Thoughts and a List.” If: book, May 2. Accessed August 1, 2017.

http://futureofthebook.org/blog/2006/05/02/defining the networked book a/. 